\title{
Avaliação da influência da espessura e da posição relativa de materiais simuladores de tecidos moles na densidade óptica de radiografias periapicais da região posterior da mandíbula \\ Evaluation of the influence of the thickness and of the relative position of soft tissues simulating materials in the optic density of periapical radiographies of the posterior region of the mandible
}

\section{Camila Porto Alegre BRAGA}

Mestranda - Programa de Pós-Graduação em Odontologia - Clínica Odontológica e Radiologia - Faculdade de Odontologia - Universidade Federal do Rio Grande do Sul - Porto Alegre - RS

\section{Aderson GEGLER}

Doutorando - Programa de Pós-Graduação em Odontologia - Estomatologia Clínica - Faculdade de Odontologia - Universidade Federal do Rio Grande do Sul - Porto Alegre - RS

\section{Vania FONTANELLA}

Professor Adjunto - Disciplina de Radiologia - Faculdade de Odontologia - Universidade Federal do Rio Grande do Sul - Porto Alegre - RS

\begin{abstract}
Resumo
Para avaliar a influência da espessura e da posição relativa de materiais simuladores de tecidos moles na densidade óptica de radiografias periapicais da região posterior da mandíbula, foram realizadas três radiografias padronizadas de peça anatômica antes e após a dissecação dos tecidos moles, da peça óssea com a interposição vestibular de músculo bovino (20 mm), cera utilidade, resina acrílica autopolimerizável e parafina nas espessuras de 20, 25 e 30mm e da peça óssea com interposição do mesmo material nas seguintes combinações: $5+15$ e 10+10mm, sendo o primeiro número referente à espessura do simulador localizado por vestibular e o segundo por lingual. As radiografias foram digitalizadas e então submetidas à análise da densidade óptica de uma área padronizada. As médias e desvios-padrão da densidade óptica de todos os grupos foram comparadas através da análise da variância, complementada pelo teste de Tukey $(\alpha=5 \%)$. O músculo bovino não reproduziu fielmente os efeitos dos tecidos moles da região posterior da mandíbula na densidade óptica da imagem radiográfica. Quando interposto somente por vestibular, o simulador que mais reproduziu a densidade óptica dos tecidos moles foi a cera, nas espessuras de 25 e 30mm. A posição do material simulador em relação à peça óssea interferiu na densidade óptica resultante. Quando interpostos por vestibular e lingual, o acrlílico em duas lâminas de $10 \mathrm{~mm}$ de espessura, a parafina e a cera com lâminas de $5 \mathrm{~mm}$ por vestibular e $15 \mathrm{~mm}$ por lingual foram as combinações que resultaram em densidade óptica que não diferiu significativamente daquela da peça com tecidos moles.
\end{abstract}

\section{UNITERMOS}

Radiografia dentária; tecidos; densidade óssea; mandíbula

\section{INTRODUÇÃO}

As propriedades das radiações ionizantes, as quais provocam alterações nos organismos vivos, representam uma séria limitação em pesquisa clínica‥ Por outro lado, estudos in vitro utilizando peças ósseas se encontram distantes do que seria a situação real ${ }^{12}$. Os estudos experimentais que objetivam avaliar a densidade óssea por diversos métodos e diferentes equipamentos devem considerar a influência dos teci- dos moles, os quais se interpõem entre o osso e a fonte de raios $\mathrm{X}^{11}$. Quando os fótons de raios $\mathrm{X}$ atravessam um objeto sofrem atenuação, então, sua intensidade é diminuída, como efeito de interações atômicas que causam sua absorção e dissipação ${ }^{8}$. Assim sendo, é de se esperar que esse fenômeno também aconteça quando um feixe de raios $\mathrm{X}$ incida sobre a mandíbula, considerando a presença de tecidos moles na trajetória desse feixe, influenciando a análise da densidade da imagem resultante. 
Estudos utilizando simuladores de tecidos moles têm sido realizados, particularmente na análise óptica da densidade óssea mandibular. A água foi o primeiro material substituto de tecido mole utilizado em medidas de radiação ${ }^{2}$. Álvares et al. ${ }^{1}$ (1969) testaram corpos de prova de diferentes materiais e observaram que a resina poliéster não saturada, a flexível e a quimicamente ativada apresentaram resultados mais próximos aos encontrados com o músculo bovino, tido como padrão-ouro do estudo.

Laskey et al. ${ }^{4}$ (1992) avaliaram a performance do equipamento Lunar®, o qual determina a densidade mineral óssea (BMD) e o conteúdo mineral ósseo (BMC) pela absorciometria duoenergética por raios $\mathrm{X}$, considerando a influência da espessura e da composição dos tecidos moles. A água foi utilizada como simulador do tecido muscular, enquanto que amostras de gordura animal simularam o tecido adiposo. Os resultados mostraram que os valores de BMD tenderam a decrescer com o aumento da espessura dos tecidos moles substitutos, enquanto que os valores do BMC aumentaram com o acréscimo em espessura destes tecidos.

Souza $^{10}$ (1998) avaliou a influência dos tecidos moles na análise da densidade óptica do tecido ósseo da região retromolar de mandíbulas humanas. Os simuladores de tecido mole utilizados foram água e cera utilidade, os quais foram comparados com uma amostra de músculo bovino, tida como o tecido mole referencial. Concluiu que houve diferença estatisticamente significativa nos valores médios da densidade óptica obtidos com e sem a presença dos simuladores e que a cera utilidade, com a espessura de $1 \mathrm{~cm}$, foi o material que melhor reproduziu os resultados obtidos com o músculo bovino. Não foram observadas diferenças estatisticamente significativas quando foram comparados os valores da densidade óptica entre os lados direito e esquerdo de uma mesma mandíbula, com e sem a presença de simuladores.

Souza et al. ${ }^{12}$ (2001) investigaram a influência dos tecidos moles muscular e adiposo sobre os níveis de cinza da região retromolar mandibular. Os simuladores de tecidos moles utilizados foram cera utilidade - para o tecido muscular - e tecido adiposo de origem bovina, em quatro diferentes espessuras. Observaram diferenças estatísticas significativas entre os valores dos níveis de cinza nas amostras de diferentes espessuras de tecido adiposo.

Meurer $^{7}$ (2000) realizou um estudo utilizando simuladores de tecidos moles para a análise óptica da densidade óssea da região parassinfisária de mandíbulas humanas radiografadas por um sistema digital. Os materiais utilizados como simuladores foram acrílico, nas espessuras de $0,5,1$ e $2 \mathrm{~cm}$, cera rosa $\mathrm{n}^{\circ} 7$ e o músculo bovino, sendo este utilizado como padrão-ouro. $\mathrm{O}$ acrílico na espessura de $2 \mathrm{~cm}$ foi o simulador que mais reproduziu os resultados do músculo bovino.

$\mathrm{Na}$ avaliação da densidade óssea, as técnicas comumente utilizadas são a absorciometria monofotônica, absorciometria duoenergética e a tomografia computadorizada quantitativa ${ }^{3,5}$. Porém, na avaliação do osso mandibular, em decorrência de sua morfologia complexa, estas técnicas são de difícil aplicação ${ }^{3}$, além de apresentarem custo elevado ${ }^{5}$. A densitometria óssea radiográfica também tem sido utilizada na determinação da densidade óssea ${ }^{3,5,13}$, porém, frente aos recentes avanços das imagens radiográficas digitais, a análise dos níveis de cinza sobre as mesmas mostrou maior sensibilidade na detecção de pequenas alterações ósseas, não demonstradas nas radiografias convencionais ${ }^{9}$.

Este estudo teve como proposta comparar três materiais simuladores de tecidos moles em diferentes espessuras e o músculo bovino a uma amostra de mandíbula humana de cadáver, fixada em formol, bem como avaliar a influência da posição relativa (vestibular ou lingual) dos simuladores na densidade óptica de radiografias periapicais da região posterior da mandíbula.

\section{Metodologia}

O presente estudo foi aprovado pelo Comitê de Ética da FO-UFRGS. De uma cabeça de cadáver fixada em formol, com características morfológicas e morfométricas de um homem adulto de estatura mediana, pertencente à disciplina de Anatomia Geral da UFRGS, foi removido um segmento ósseo do corpo mandibular, com $4,5 \mathrm{~cm}$ de extensão mésiodistal, juntamente com os tecidos moles vestibulares e linguais da região.

Desta peça foram obtidas três radiografias periapicais padronizadas, identificadas como POTM (peça óssea com tecidos moles) 1 a 3 , conforme os passos a seguir descritos:

- um posicionador periapical (Jon - SP) foi preparado, de forma a se obter, em resina acrílica autopolimerizável (Artigos Odontológicos Clássico - SP), o registro oclusal dos dentes da peça mandibular, em substituição ao dispositivo de mordida; 
AVALIAÇÃO DA INFLUÊNCIA DA ESPESSURA E DA POSIÇÃO RELATIVA DE MATERIAIS SIMULADORES DE TECIDOS MOLES NA DENSIDADE ÓPTICA DE RADIOGRAFIAS PERIAPICAIS DA REGIÃO POSTERIOR DA MANDÍBULA

- este posicionador foi fixado ao cilindro localizador de um aparelho radiográfico odontológico Pro 70® (Prodental Equipamentos Odontológicos Ltda - Ribeirão Preto - SP), permitido assim a reprodutibilidade geométrica das exposições radiográficas;

- foram utilizados filmes radiográficos periapicais $\mathrm{n}^{\circ} 2$, de sensibilidade F (Insight ${ }^{\circledR}$ - Kodak - São Paulo), expostos com $70 \mathrm{kVp}, 7 \mathrm{~mA}$ e $0,4 \mathrm{~s}$;

- até o final do experimento, os filmes expostos foram armazenados em local protegido de radiação, calor e umidade;

- após obtidas todas as exposições, os filmes foram simultaneamente processados pelo método automático, em máquina processadora modelo 9000® (DENT-X - EUA), utilizando soluções X-Omat ${ }^{\circledR}$ (Kodak - São Paulo), em ciclo de 4,5 min.

A seguir, os tecidos moles da peça mandibular foram dissecados. Após transcorridos oito dias, de forma a permitir a perda de água da peça óssea, a mesma foi reposicionada através do registro oclusal e obtidas 3 radiografias, denominadas $\mathrm{PO}$ (peça óssea) 1 a 3, com os mesmos parâmetros anteriormente descritos.

Foram, então, preparados os simuladores de tecidos moles, constituídos de três diferentes materiais: parafina (Bandeirante Química - SP), cera utilidade (Artigos Odontológicos Clássico - SP) e resina acrílica auto-polimerizável (Artigos Odontológicos Clássico - SP) na forma de lâminas com 3,5 x 4,5 $\mathrm{cm}$, com espessuras de $5,10,20,25$ e $30 \mathrm{~mm}$ para cada material.

A peça óssea foi, então, radiografada três vezes com cada um dos simuladores, nas espessuras de 20 , 25 ou $30 \mathrm{~mm}$, posicionado junto à face vestibular da mandíbula, com os parâmetros anteriormente descritos, e as radiografias denominadas P20, P25, e P30 1 a 3 (parafina nas diferentes espessuras); C20, C25 e C30 1 a 3 (cera utilidade nas diferentes espessuras); e A20, A25 e A30 1 a 3 (resina acrílica nas diferentes espessuras).

Para verificar se a posição relativa do material simulador (vestibular ou lingual) interfere nos resul- tados, foram obtidas, seguindo a mesma padronização, três radiografias com dois simuladores do mesmo material, posicionados respectivamente por vestibular e lingual, denominados P5+15 e P10+10 1 a 3 (parafina), $C 5+15$ e $\mathrm{C} 10+101$ a 3 (cera utilidade), $\mathrm{A} 5+15$ e A10+10 1 a 3 (resina acrílica), onde o primeiro número corresponde a espessura em milímetros localizada por vestibular e o segundo número a espessura por lingual.

Foi também preparado um corpo de prova em músculo bovino, na forma de uma lâmina com 3,5 x $4,5 \mathrm{~cm}$, com $20 \mathrm{~mm}$ de espessura. No sentido de evitar a deformação da peça, a mesma foi fixada através de fios de aço em uma armação metálica. Após obtidas as radiografias denominadas POMB (músculo bovino) 1 a 3, o mesmo foi congelado. Foram então obtidas as imagens denominadas POMBC (simulador de tecidos: músculo bovino congelado) 1 a 3 . Após o descongelamento, o músculo bovino foi fixado em formalina neutra tamponada a $10 \%$, por 24 horas, e então obtidas as radiografias denominadas POMBFOR 1 a 3 .

Os 60 filmes expostos e processados de forma padronizada foram digitalizados através de um scanner de mesa com leitor de transparência modelo Epson Perfection $2540 \AA$, em tamanho original, sem ajuste de brilho ou contraste, em 300 dpi e 8 bits (256 tons de cinza). Os filmes do mesmo grupo foram posicionados sobre a mesa do scanner, com o auxílio de uma máscara de digitalização em acrílico preto, com as respectivas saliências das marcas identificadoras voltadas para a face de vidro da mesa, alinhados em uma coluna de três filmes, e digitalizados simultaneamente. As imagens resultantes foram codificadas e armazenadas em disco no formato JPEG, com compressão mínima (nível 12).

No programa Adobe Photoshop v. 6.0 (Adobe Inc, San José, CA, EUA), as imagens foram recortadas de forma padronizada, de maneira que resultassem nas mesmas dimensões e registrassem a mesma área.

A seguir, através do programa ImageTool v. 3.0 (UTHSCSA, San Antonio, TX, EUA), um examinador que desconhecia a que grupo pertenciam as imagens obteve os valores de densidade óptica de toda a área da imagem (Figura 1). 
AVALIAÇÃO DA INFLUÊNCIA DA ESPESSURA E DA POSIÇÃO RELATIVA DE MATERIAIS SIMULADORES DE TECIDOS MOLES NA DENSIDADE ÓPTICA DE RADIOGRAFIAS PERIAPICAIS DA REGIÃO POSTERIOR DA MANDÍBULA

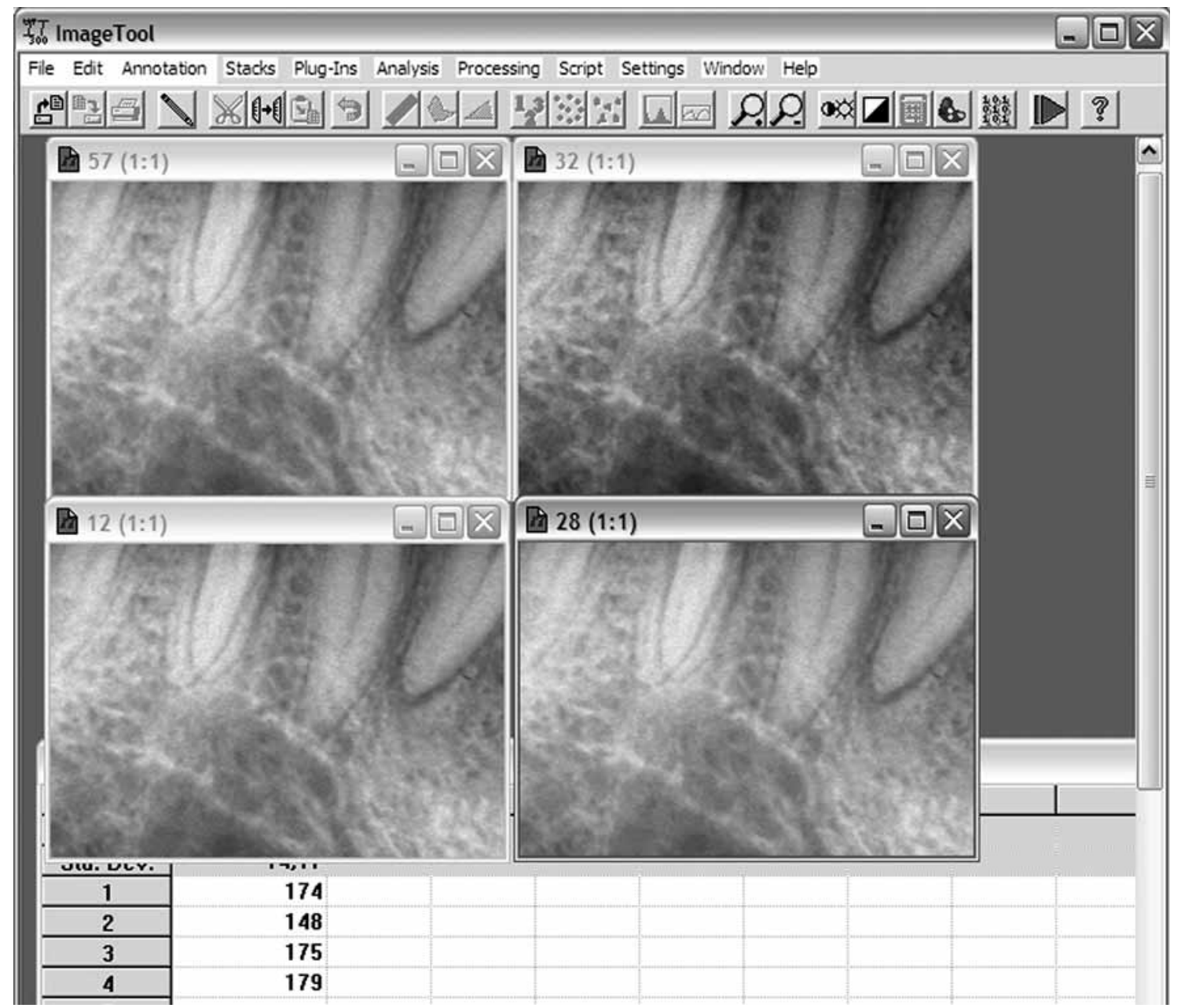

FIGURA 1 - Tela do programa ImageTool durante a obtenção dos valores médios de densidade óptica de quatro das imagens do estudo. As imagens codificadas como 57, 32, 28 e 12 correspondem, respectivamente, a: POTM, PO, POMB e A10+10.

Os valores médios e os desvios padrão dos níveis de cinza (em densidade de pixels) de todos os grupos foram comparados através da Análise de Variância, complementada pelo Teste de Tukey, ao nível de significância de $5 \%$.

\section{Resultados e discussão}

Os valores médios e desvios padrão de densidade de pixels são apresentados na Tabela 1. Ob- serva-se que a média de densidade óptica da peça com tecidos moles (PTM) foi significativamente maior que a da peça óssea dissecada (PO), resultando em imagens mais claras. Este resultado está de acordo com estudos anteriores ${ }^{7,10,12}$ e comprova a necessidade do uso de um simulador de tecidos moles quando se avalia densidade óptica da região posterior da mandíbula. 
AVALIAÇÃO DA INFLUÊNCIA DA ESPESSURA E DA POSIÇÃO RELATIVA DE MATERIAIS SIMULADORES DE TECIDOS MOLES NA DENSIDADE ÓPTICA DE RADIOGRAFIAS PERIAPICAIS DA REGIÃO POSTERIOR DA MANDÍBULA

Tabela 1 - Valores médios de densidade óptica e desvios padrão em imagens dos diferentes grupos de radiografias digitalizadas

\begin{tabular}{l|l|l}
\hline Grupo & Média & Desvio padrão \\
\hline POMB & $179,52^{\mathrm{A}}$ & 0,48 \\
P30 & $179,42^{\mathrm{A}}$ & 0,46 \\
POMBFOR & $179,35^{\mathrm{A}}$ & 0,37 \\
A30 & $179,34^{\mathrm{A}}$ & 0,41 \\
POMBC & $176,62^{\mathrm{B}}$ & 0,41 \\
A25 & $176,62^{\mathrm{B}}$ & 0,44 \\
P25 & $175,93^{\mathrm{B}}$ & 0,48 \\
A10+10 & $175,63^{\mathrm{BC}}$ & 0,32 \\
C30 & $175,55^{\mathrm{BC}}$ & 0,41 \\
C25 & $175,44^{\mathrm{BC}}$ & 0,42 \\
POTM & $174,51^{\mathrm{C}}$ & 0,44 \\
P5+15 & $174,49^{\mathrm{C}}$ & 0,43 \\
C5+15 & $174,49^{\mathrm{C}}$ & 0,43 \\
C20 & $173,11^{\mathrm{D}}$ & 0,44 \\
P20 & $173,10^{\mathrm{E}}$ & 0,43 \\
A20 & $172,73^{\mathrm{E}}$ & 0,48 \\
A5+15 & $172,15^{\mathrm{E}, \mathrm{F}}$ & 0,43 \\
C10+10 & $170,37^{\mathrm{F}}$ & 0,43 \\
P10+10 & $167,44^{\mathrm{C}}$ & $148,56^{\mathrm{H}}$ \\
PO & & 0,43 \\
\hline & & \\
\hline
\end{tabular}

Médias seguidas de letras distintas diferem significativamente através da Análise de Variância complementada pelo Teste de Comparações Múltiplas de Tukey, ao nível de significância de 5\%.

Estudos atuais realizados em peças ósseas comparam simuladores de tecidos moles ao músculo bovino $^{1,7,10}$ contudo este apresenta inconvenientes de manipulação e pode não representar com exatidão a estrutura de diferentes tecidos não mineralizados associados à mandíbula humana.
Quando se utilizou músculo bovino (POMB) como simulador, o valor médio de densidade óptica foi significativamente maior (imagem mais clara) que para POTM, contra-indicando que o mesmo seja utilizado como referencial na pesquisa de materiais simuladores de tecidos moles. A fixação em formol do músculo 
bovino (POMBFOR) não interferiu significativamente na densidade óptica. Desta forma, presume-se que a utilização, no presente estudo, da peça de cadáver fixada em formol não tenha interferido nos resultados. O congelamento do músculo bovino (POMBC) resultou em densidade óptica média significativamente menor (imagem mais escura) do que quando o mesmo material não estava congelado.

Quando comparadas as imagens nas quais foram utilizados simuladores em parafina, cera utilidade e resina acrílica auto-polimerizável posicionados somente por vestibular da peça óssea, a diferença de espessura do simulador interferiu significativamente nos valores de densidade óptica média, exceto para C25 e C30, os quais foram os únicos grupos que não apresentaram diferenças significativas das imagens POTM. Esses resultados condizem com os estudos nos quais a cera dental e o acrílico foram testados ${ }^{7,10}$.

Comparando-se as mesmas espessuras de diferentes materiais, não foram observadas diferenças significativas entre elas, exceto para C30, cuja densidade óptica média foi menor (imagem mais escura) que para a mesma espessura em acrílico e parafina.

Quanto à posição relativa do simulador, observouse que a presença do mesmo somente por vestibular resulta em imagens com densidade óptica diferente de quando a mesma espessura é dividida e interposta por vestibular e lingual, para todos os materiais testados. Quando a maior espessura do material foi interposta por lingual, as imagens resultantes apresentaram-se significativamente diferentes do que quando a espessura foi igualmente distribuída ou interposta somente por vestibular. Contudo, os materiais testados não apresentaram comportamento consistente. A densidade física de cada material é, possivelmente, a variável responsável pelas diferenças encontradas.
Das combinações testadas, as situações que não apresentaram diferenças significativas de densidade óptica quando comparadas à peça óssea com tecidos moles foram: A10+10, C30, C25, P5+15 e C5+15. Considerando a facilidade de confecção do simulador e sua posterior estabilidade de forma, recomenda-se o emprego de $2 \mathrm{~cm}$ de acrílico, igualmente distribuído por vestibular e lingual, nos estudos que objetivem avaliar a densidade óptica na região posterior da mandíbula.

Cabe salientar que este estudo apresenta como limitações o fato de ter utilizado apenas uma mandíbula, o que se explica pela dificuldade na obtenção de peças de cadáver passíveis de utilização, e que não foram testadas diferentes combinações de fatores elétricos, geométricos e receptores de imagem.

\section{Conclusões}

- O músculo bovino na espessura de $20 \mathrm{~mm}$, utilizado como padrão-ouro em pesquisas de materiais simuladores, não reproduz fielmente os efeitos dos tecidos moles da região posterior da mandíbula sobre densidade óptica da imagem radiográfica.

- Quando interposto somente por vestibular, o simulador que mais reproduziu a densidade óptica dos tecidos moles foi a cera, nas espessuras de 25 e $30 \mathrm{~mm}$.

- A posição do material simulador em relação à peça óssea interfere na densidade óptica resultante. Quando interpostos por vestibular e lingual, o acrílico em duas lâminas de $10 \mathrm{~mm}$ de espessura, a parafina e a cera com lâminas de $5 \mathrm{~mm}$ por vestibular e $15 \mathrm{~mm}$ por lingual foram as combinações que resultaram em densidade óptica que não diferiu significativamente daquela da peça com tecidos moles.

\begin{abstract}
The aim of this study was to evaluate the influence of the thickness and the relative position of materials simulating soft tissues in the optic density of periapical radiographies of the posterior region of the mandible. Three standardized radiographies were obtained from a cadaver posterior mandibular segment before and after the dissection of soft tissues, with the buccal interposition of bovine muscle $(20 \mathrm{~mm})$, wax, self-cured acrylic resin and paraffin $(20 \mathrm{~mm}, 25 \mathrm{~mm}$, and $30 \mathrm{~mm}$ ), and with interposition of the same material in the following combinations: $5+15 \mathrm{~mm}$ and $10+10 \mathrm{~mm}$, being the first number the thickness of the simulator placed at buccal and the second at lingual aspect. The radiographies were digitized and submitted to the analysis of the optic density of a standardized area. The averages and standard deviations of the optic density of all the groups were compared through the ANOVA, complemented by Tukey's test $(\alpha=5 \%)$. The bovine muscle did not reproduce the effect of soft tissues in the optic density of the radiographic image. When placed only at the buccal aspect the wax (25 and 30mm) was the material that better simulated the optic density of soft tissues. The relative position of the material affected the resultant optic density. When placed at both buccal and lingual aspects, the acrilic resin in two blades of $10 \mathrm{~mm}$ of thickness each, the paraffin and the wax in blades of $5 \mathrm{~mm}$ for buccal and of $15 \mathrm{~mm}$ for lingual aspect resulted in optic density that does not differs from that one of the cadaver mandible.
\end{abstract}

\title{
UNITERMS
}

Radiography, dental; tissues; bone density, mandible 


\section{REFERÊNCIAS}

1. Alvares CL, Tavano O, Freitas JAS. Estudo comparativo entre alguns materiais como substitutos para o tecido mole, no que concerne à absorção de raios X e emissão de radiação secundária. Estomatol Cult. 1969 dez.; 3(2):153-66

2. Cook JE, Cunningham JL. The assessment of fracture healing using dual x-ray absorptiometry: a feasibility study using phantons. Phys Med Biol. 1995 Jan.; 40 (1):119-36.

3. Jeffcoat MK, Lewis CE, Reddy MS, Wang CY, Redford M. Post-menopausal bone loss and its relationship to oral bone loss. Periodontol. 2000 June; 23:94-102.

4. Laskey MA, Lyttle KD, Flaxman ME, Barber RW. The influence of tissue depth and composition on the performance of the Lunar dualenergy X-ray absorptiometer whole-body scanning mode. Eur J Clin Nutr. 1992 Jan.; 46(1):39-45.

5. Louzada M, Mesquita Filho J. Densidade óssea em função da idade cronológica de coelhos normais, através da densitometria radiográfica. ln: Anais do Congresso Brasileiro de Biomecânica; 1999, Florianópolis: UDESC; 1999. p 559-64.

6. Magalhães SD, Gonçalves OD, Rizzo P. Scattering of $60 \mathrm{keV}$ photons by biological material and influence in diagnosis radiology. Med Phys. 1996 Sept.; 23(9):1635-42.

7. Meurer E. Análise óptica da densidade óssea da região parassinfisária por um sistema de radiografia digital, utilizando simuladores de tecidos moles [dissertação]. Porto Alegre: - Faculdade de Odontologia PUCRS; 2000.

8. Pietrobelli A, Formica C, Wang Z, Heymsfield SB. Dual-energy X-ray absorptiometry body composition model: review of physical concepts. Am J Physiol 1996 Dec.; 271(6):941-51.
9. Sarmento VA, Pretto SM, Costa NP. Entendendo a imagem digitalizada. Rev Odonto Cienc. 1999 jun.; 14(27):171-8.

10. Souza PHC. Análise óptica da densidade óssea retromolar mandibular por meio de imagens digitalizadas utilizando simuladores de tecidos moles. [Dissertação]. Porto Alegre: Faculdade de Odontologia PUCRS; 1998.

11. Souza PHC, Costa NP, Puppin AAC. Análise óptica da densidade óssea retromolar mandibular por meio de imagens digitalizadas, utilizando simuladores de tecidos moles. Rev Odont Ciênc. 1999 dez.; 14(28):2753.

12. Souza PHC, Costa NP, Veeck EB. Influência dos tecidos moles nos níveis de cinza da região retromolar mandibular, utilizando filmes Ektaspeed Plus e o programa de imagens digitalizadas Digora. Rev Odont Ciênc. 2001 set./dez.; 16(34):268-74.

13. Villarreal PM, Junquera LM, Martinez A, Garcia-Consuegra L. Study of mandibular fracture repair using quantitative radiodensitometry: a comparison between maxillomandibular and rigid internal fixation. J Oral Maxillofac Surg. 2000 July.; 58(7):776-81.

Recebido em: 17/04/06 Aprovado em: 19/10/06

Profa. Dra. Vania Fontanella Rua Cel. Paulino Teixeira, 169/403 90420-160 - Porto Alegre - RS vaniafontanella@terra.com.br Telefone/fax: 51-33331927 